\title{
Transdermal carbamate poisoning - a case of misuse
}

\author{
Lalit Kumar Rajbanshi \\ Department of Anaesthesiology and Critical care, Birat Medical College and Teaching Hospital, Biratnagar, \\ Nepal
}

\section{Correspondence}

Dr. Lalit Kumar Rajbanshi

Birat medical college and teaching hospital, Biratnagar, Nepal

\section{Email:}

lalitrajbanshi@gmail.com

DOI: http://dx.doi.org/10.3126/ jcmsn.v12i4.16418

Article received: Aug $8^{\text {th }} 2016$ Article accepted: Dec $20^{\text {th }} 2016$

\section{ABSTRACT}

Acute pesticide poisoning is a common mode of intentional self harm. Oral ingestion is the usual mode of poisoning. However, inhalation, accidental or occupational transdermal exposure leading to acute or chronic poisoning can be the other route of poisoning. It has been seen that the purpose of poising is suicidal intensity in most of the cases. We report an unusual case where the victim had acute pesticide poisoning through transdermal route that was intended for non suicidal purpose. The patient was managed successfully with immediate decontamination and adequate antidote.

Key words: Pesticide poisoning; skin decontamination; transdermal route

Citation: Rajbanshi LK. Transdermal carbamate poisoning - a case of misuse. JCMS Nepal. 2016;12 (4):187-8.

\section{INTRODUCTION}

Pesticide poisonings are among the most common modes of acute poisoning in an agricultural country like Nepal. The usual route of administration can be oral, inhalation, parenteral and occasionally transdermal; the oral route being the most common one. There is an intention to cause self harm in most of the poisoning. Occupational exposure in farmers and accidental exposure in children can be occasional cause of poisoning through transdermal route. There are only few reports for accidental dermal exposure and acute poisoning. ${ }^{1}$ we report a case of carbamate poising after skin exposure of the compound for non suicidal purpose.

\section{CASE REPORT}

A 52 years male from rural part of Nepal presented to emergency department with the history of altered sensorium and vomiting for last three hours. He did not have any premorbid and psychiatric illness and was happy with his family. On examination his GCS was 11/15 ( E 4 V2 M5) and full of sweats all over the body. His vitals were HR 110/min, RR 28 / min, Sp02 98\% with six litres of oxygen via face mask and BP 110/80 mmHg. Chest had bilateral equal air entry with normal vesicular breath sounds except few conducted sounds at the basal region. Pupils were two $\mathrm{mm}$ bilateral and reacting to light. His hematological as well as biochemical laboratory investigations were all unremarkable.
ABG showed respiratory alkalosis and chest $\mathrm{X}$ ray was normal. Random blood sugar and electrolytes were normal.

On further evaluation of the history, his wife told that patient was fine three hours ago when he applied a pesticide all over his body except his face. $\mathrm{He}$ wanted to kill mites in his body with this pesticide and for this he mixed approximately $5 \mathrm{gm}$ of carbamate ( Carbofuran 3\%) in $30 \mathrm{ml}$ of coconut oil and applied all over his body. After half an hour, he developed dizziness, nausea and sweating.

So with this history, diagnosis of acute carbamate poisoning was confirmed. The patient was initially resuscitated following $\mathrm{ABC}$ (airway, breathing and circulation) protocol and was atropinized with 30 $\mathrm{mg}$ of atropine once the diagnosis of carbamate poisoning was made. Patient was shifted to medical ICU and was managed with continuous infusion of atropine starting with $12 \mathrm{mg}$ of atropine per hour. Atropine was gradually decreased and finally stopped on $9^{\text {th }}$ day as the patient clinically improved and was shifted to ward next day.

\section{DISCUSSION}

Carbofuran, the pesticide used in our case is highly toxic carbamate with an oral LD50 of 8 to $14 \mathrm{mg} / \mathrm{kg}$ in rats and $19 \mathrm{mg} / \mathrm{kg}$ in dogs. ${ }^{2}$ Unlike organophosphates, carbamate causes reversible carbamylation of acetylcholinesase enzyme allowing accumulation of acetylcholine molecule 
and overstimulation of acetylcholine receptors in synapses of the autonomic nervous system, CNS, and neuromuscular junctions. ${ }^{3}$ Patient can present with the features of cholinergic crisis within 24 hours. Subsequently intermediate syndromes with respiratory muscle weakness, cranial nerve palsies or proximal muscle weakness can develop within 24 to 96 hours of cholinergic crisis. Some patients develop delayed polyneuropathy within two to three weeks. ${ }^{4,5}$

Carbofuran can easily be absorbed by inhalation, ingestion and through the skin. Most of the transdermal exposures are occupational and cause delayed manifestations. ${ }^{6}$ In our case, the poisoning was acute and the exposure was neither occupational nor accidental. There was no intention to cause deliberate harm to himself. The absorption depends on the site of application, skin condition, type of pesticide, and the duration of contact. Sweating, increased blood circulation or moist areas can enhance transdermal absorption.?

Carbofuran is highly lipophilic and the oil based preparation used in our case might have enhanced the transdermal absorption and hence precipitating the clinical manifestation even though the amount was very low. Absorption continues as long as the pesticide remains in contact with the skin and hence the need for immediate cleansing. In our case we used normal soap water for cleaning the body as soon as we confirmed the history. Rapid decontamination of the exposed part is an essential step to stop further absorption.

The treatment for the carbamate poisoning is specific anticholinergic antidote, atropine and supportive measure. Oxime therapy is controversial and is not recommended in carbamate poisoning because of possible toxicity with carbamates. ${ }^{8,9} \mathrm{We}$ didn't use oxime therapy in our case.

\section{CONCLUSION}

Our case report high light the fact that acute poisoning of commonly available pesticides can occur through any route and people can misuse pesticides for non-suicidal purpose which may lead to lethal clinical outcome. We conclude that the improper knowledge regarding the use of such compounds is the major reason for non accidental lethal use.
2. Micromedex I. Registry of Toxic Effects of Chemical Substances: NIOSH; 1991.

3. Lifshitz M, Shahak E, Bolotin A, Sofer S. Carbamate poisoning in early childhood and in $\square$ adults. J Toxicol Clin Toxicol. 1997;35(1):25-27. DOI: 10.3109/15563659709001161. PMID:9022648.

4. Cherian MA, Roshini C, Peter JV, Cherian AM. Oximes in organophosphorus poisoning. Indian $\mathrm{J}$ Crit Care Med. 2005;9:155-63. DOI: 10.4103/0972-5229.19682.

5. Kamanyire R, Karalliedde L. Organophosphate toxicity and occupational exposure. Occup Med (Lond) 2004;54:69-75.c

6. Kamanyire R, Karalliedde L. Organophosphate toxicity and occupational exposure. Occup Med (Lond) 2004;54:69-75. DOI: $10.1093 /$ occmed/kqh018.

7. Paul Prabhakar Abhilash Kundavaram, Swaratika Majumdar, and Sohini Das. Intra-aural Route of Insecticide Poisoning Toxicol Int. 2013 May-Aug; 20(2): 192-193.

8. Kurtz PH. Pralidoxime in the treatment of carbamate intoxication. Am J Emerg Med 1990 Jan;8(1):68-70. DOI: 10.1016/0735-6757(90)90299-F.

9. Rosman Y1, Makarovsky I, Bentur Y, Shrot S, Dushnistky T, Krivoy A.Carbamate poisoning: treatment recommendations in the setting of a mass casualties event.Am J Emerg Med. 2009 Nov;27(9):1117-24. DOI: 10.1016/j.ajem.2009.01.035. PMID:19931761.

\section{REFERENCES}

1. Willemijn van Heel and Said Hachimi-Idrissi.Accidental organophosphate insecticide intoxication in children: a reminder.Int J Emerg Med. 2011; 4: 32. DOI: 10.1186/1865-1380-4-32. PMID:21676238. 